\title{
Processing and Characterization of Fe-Mn-Cu-Sn-C Alloys Prepared by Ball Milling and Spark Plasma Sintering
}

\author{
Elżbieta Bạczek, Janusz Konstanty, Andrzej Romański, Marcin Podsiadło, and Jolanta Cyboroń
}

\author{
(Submitted August 22, 2017; in revised form December 31, 2017; published online January 29, 2018)
}

\begin{abstract}
In this work, Fe-Mn-Cu-Sn-C alloys were prepared by means of powder metallurgy (PM). Powder mixtures were ball-milled for 8,30 and $120 \mathrm{~h}$ and densified to $<1 \%$ porosity using spark plasma sintering (SPS) at $900{ }^{\circ} \mathrm{C}$ and $35 \mathrm{MPa}$. After consolidation, all samples of the $\mathrm{Fe}$ alloys were characterized by $\mathrm{x}$-ray diffraction (XRD), scanning electron microscopy (SEM), hardness and flexural strength tests. Resistance to abrasive wear was evaluated in both three-body abrasion and two-body abrasion tests. The SEM observations revealed an evident dependence of grain size and microstructural homogeneity on milling time. The XRD analysis showed a marked increase in austenite content in the as-sintered specimens with milling time. Although the proportion of deformation-induced martensite was small, the strengthening effect of abrasion on the subsurface layer of the investigated alloys was clearly indicated by Knoop hardness measurements.
\end{abstract}

Keywords ball milling, diamond-impregnated composite, Fe alloys, powder metallurgy, spark plasma sintering, wear resistance

\section{Introduction}

Sintered diamond-impregnated tools consist of diamond crystals embedded in a metallic matrix most often composed of: cobalt, copper, nickel, tin, iron, tungsten and tungsten carbide. Cobalt has long been the most valued matrix material used for professional tools, due to its excellent diamond retention characteristics and sinterability of commercial Co powders. As the price of cobalt is highly unstable and increasingly contributes to the overall tool cost, the recent industrial trend is toward replacement of cobalt-containing matrices with other, preferably iron alloys produced by PM (Ref 1-10), by various routes (Ref 11, 12). In our previous publications, we have identified and reported on such a promising alloy $\mathrm{Fe}-12 \%$ $\mathrm{Mn}-6.4 \% \mathrm{Cu}-1.6 \% \mathrm{Sn}-0.6 \% \mathrm{C}$ (Ref 6-9). Mixed powders were ball-milled and hot-pressed in a graphite mold. Before evaluating diamond retention by expensive industrial-type tests, mechanical and tribological properties of the prospective matrix material are explored. It is important to find the best processing route, and therefore, spark plasma sintering (SPS) technique is now considered. It is a variant of pressure-assisted sintering which has the merit of high heating rates, broad range of sintering temperature and short sintering time (Ref 13,14$)$. A

Elżbieta Bączek, Marcin Podsiadło, and Jolanta Cyboron, The Institute of Advanced Manufacturing Technology, Wroclawska 37A Str., 30-011 Kraków, Poland; and Janusz Konstanty and Andrzej Romański, AGH University of Science and Technology, Al. A. Mickiewicza 30, 30-059 Kraków, Poland. Contact e-mail: elzbieta.baczek@ios.krakow.pl. typical SPS equipment is fitted with a vacuum chamber, wherein a graphite die is positioned, and a hydraulic pressing system for the application of pressure. First, the diamond-metal powder mixture is axially compacted inside the graphite die until the desired pressure is reached. Then the pressurized powder is heated up to the sintering temperature by passing a high-frequency pulsed current through the graphite die and, in the case of conductive materials, also through the sintered powder. The transition of current pulses through the powder bed leads to the formation of plasma discharges/sparks between adjacent powder particles. The aforementioned phenomena and very fast heating rates (up to $800 \mathrm{~K} / \mathrm{min}$ ) make SPS viable for commercial use (Ref 13,15$)$. The technique can be successfully used for synthesis and processing of ceramics, metals, cermets, intermetallics, etc. (Ref 16-19). The pulsed current, which differentiates SPS technique from the conventional hot pressing, has also been tested as an alternative method of heating in ultrahigh-pressure synthesis of superhard materials (Ref 20, 21). It can also offer new ways for the manufacture of materials having properties tailored for special cutting or grinding tools. In the present work, we discuss the feasibility of SPS technique in densification of ball-milled $\mathrm{Fe}-\mathrm{Mn}-\mathrm{Cu}-\mathrm{Sn}-\mathrm{C}$ alloy powders intended for the fabrication of diamond tools used to process abrasive materials.

\section{Materials and Methods}

\subsection{Materials}

The ball-milled Fe-Mn-Cu-Sn-C alloy powder, which contained 12 wt. $\% \mathrm{Mn}, 6.4$ wt.\% Cu, 1.6 wt.\% $\mathrm{Sn}$ and 0.6 wt. $\%$ C, was prepared from commercially available powders. Spongy iron, ground ferromanganese and water-atomized tin-bronze powders were provided by Höganäs, ESAB and NeoChimie, respectively.

The morphology and chemical composition of the starting powders are shown in Fig. 1 and Table 1, respectively. 

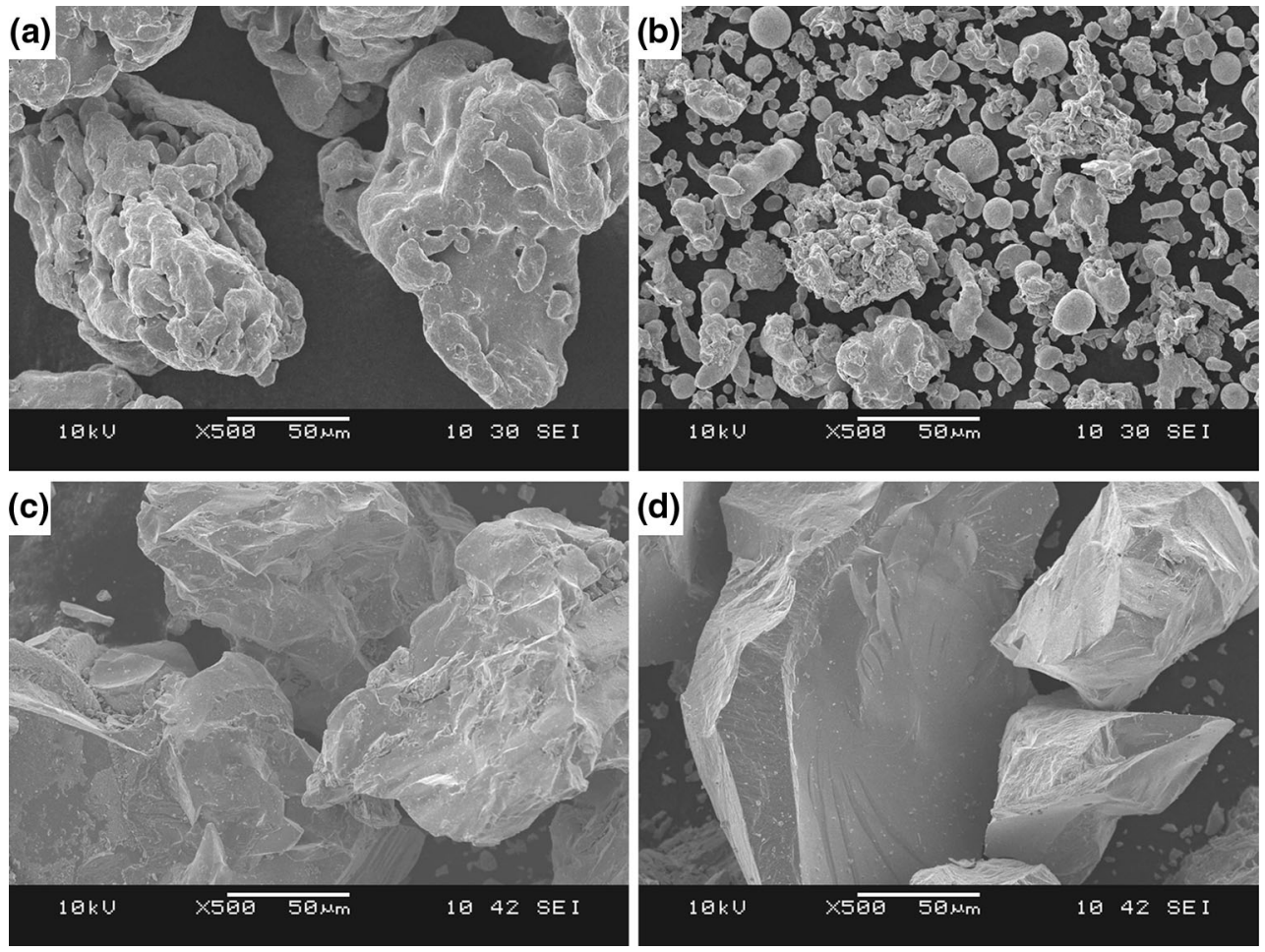

Fig. 1 SEM images of the starting powders: (a) spongy iron grade NC 100.24, (b) tin-bronze grade NAM40-80/20, (c) ground ferromanganese grade XH1210, (d) ground ferromanganese grade XH1218

Table 1 Chemical composition and particle size of the starting powders

\begin{tabular}{|c|c|c|c|c|c|c|c|}
\hline \multirow[b]{2}{*}{ Powder } & \multirow[b]{2}{*}{ Powder grade } & \multicolumn{5}{|c|}{ Chemical composition, wt.\% } & \multirow[b]{2}{*}{ Mean particle size, $\mu \mathrm{m}$ (a) } \\
\hline & & $\mathrm{Fe}$ & Mn & $\mathbf{C u}$ & Sn & $\mathbf{C}$ & \\
\hline Iron & $\mathrm{NC} 100.24$ & 100 & $\ldots$ & $\ldots$ & $\ldots$ & $\ldots$ & 85 \\
\hline Ferromanganese & XH1210 & bal & 80 & $\ldots$ & $\ldots$ & 7.0 & 134 \\
\hline Ferromanganese & XH1218 & bal & 80.5 & $\cdots$ & $\ldots$ & 1.5 & 143 \\
\hline Tin-bronze & NAM40-80/20 & $\ldots$ & $\ldots$ & $\ddot{80}$ & 20 & $\ldots$ & 23 \\
\hline
\end{tabular}

\subsection{Ball Milling}

Prior to milling, the powders were mixed in the required proportions for $10 \mathrm{~min}$ in a Turbula-type mixer. The mixture was subsequently divided into three equal parts, which were ball-milled in a roll mill for 8,30 or $120 \mathrm{~h}$ in air. The milling container was filled with powder and $12 \mathrm{~mm} 100 \mathrm{Cr} 6$ steel balls to $50 \%$ of its volume and rotated at $70 \%$ critical speed. The ball-to-powder weight ratio was 10:1. After milling, the particle shape and size were examined by SEM and sieve analysis, respectively. In order to determine the effect of milling time on the phase composition of $\mathrm{Fe}-\mathrm{Mn}-\mathrm{Cu}-\mathrm{Sn}-\mathrm{C}$ alloy powder, an $\mathrm{x}$ ray phase analysis was performed.

\subsection{Spark Plasma Sintering (SPS)}

The ball-milled powders were sintered using the HPD 5 type SPS system. Each powder was placed in a graphite die, $30 \mathrm{~mm}$ in diameter, axially pressed under $35 \mathrm{MPa}$, heated to $900{ }^{\circ} \mathrm{C}$ at $100 \mathrm{~K} / \mathrm{min}$ and held at temperature for $5 \mathrm{~min}$ in argon. A 0.5 $\mathrm{mm}$-thick graphite foil was used to isolate the sintered powder from graphite punches in order to facilitate extraction of the sintered body. The graphite die was additionally wrapped with a carbon blanket to minimize heat losses during sintering.

Typical SPS curves are presented in Fig. 2.

\subsection{Characterization of Sintered Specimens}

The as-sintered densities were measured using the Archimedes' principle. Hardness measurements were carried out using the Vickers and Knoop tests. Ten indentations were made on each specimen. The phase stability was checked in order to assess the effect of strain-induced martensitic transformation of austenite on the alloy's resistance to abrasion. To do this, specimens representative of each alloy were examined by means of x-ray diffraction. XRD patterns were obtained using the copper radiation $\left(\lambda_{\mathrm{Cu}}=1.5406 \AA\right)$. The quantitative phase analysis performed using the Rietveld refinement and HighScore PANalytical software. Therefore, by using XRD phase analysis it was possible to determine the proportion of $(\gamma \mathrm{Fe})$ to $(\alpha \mathrm{Fe})$ in the subsurface layer of each specimens both after grinding on \#220 $\mathrm{SiC}$ paper and after polishing on $1 \mu \mathrm{m}$ diamond in order to predict 
the amount of martensite which can be generated beneath the working face of the tool by abrasion. Two samples of each alloy $ø 30 \times 5 \mathrm{~mm}$ were then cut into two bend specimens $7 \times 4.5 \times 29.5 \mathrm{~mm}$, which were subsequently subjected to a nonstandard three-point bending test to determine the transverse rupture strength (TRS), $0.2 \%$ offset yield strength (OYS) and amount of plastic deformation at failure $\left(\varepsilon_{\mathrm{pl}}\right)$. The testing procedure is explained schematically in Fig. 3. The fracture surfaces were examined by SEM and the broken bending bars were subsequently used to produce abrasive wear test pieces. The wear rate was studied under three-body and two-body abrasion conditions using the microwear test (MWT) described in Ref 22, 23 and modified MWT described in Ref 24, respectively.

\section{Results and Discussion}

\subsection{Ball Milling}

The particle size and morphology of all composite powders were observed under the SEM, whereas the particle size was

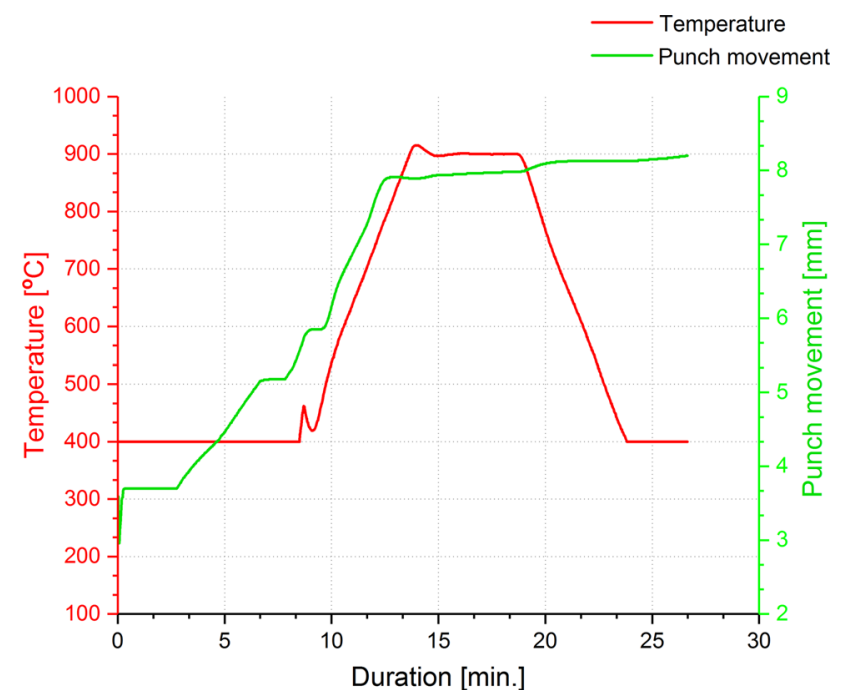

Fig. 2 Temperature and punch movement SPS curves recorded during densification of Fe-Mn-Cu-Sn-C alloy powder milled for $8 \mathrm{~h}$ also examined by sieve analysis. Figure 4 shows an irregular structure of powders with different ball milling times. During milling, the powder particles are repeatedly flattened, workhardened and fractured, and welded together. The Fe-Mn-CuSn-C alloy powder particles flatten during the early stages of milling (Fig. 4a), but, due to heavy working, particle fracturing soon prevails over welding, resulting in finer (Fig. 5) and more equiaxed particles after milling for $120 \mathrm{~h}$ (Fig. 4c). The average size of powder particles decreased from 54 to $31 \mu \mathrm{m}$ after prolonging the milling time from 8 to $120 \mathrm{~h}$. As compared with Fe-Ni-based materials described in Ref 9, after $120 \mathrm{~h}$ of milling the powders are characterized by a flaky shape and a characteristic layered microstructure with very fine lamellar spacing. The average particle size of $\mathrm{Fe}-\mathrm{Ni}$ alloy powders increases with milling time.

Figure 6 which shows XRD patterns of ball-milled powders shows that the peaks of the individual phases are widened due to the progressive plastic deformation of the powder particles. The peaks of tin-bronze disappear with increasing milling time, which may indicate progression of mixing the bronze powder particles within the iron particles. It is not possible to exclude the occurrence of diffusion processes whose intensity can be increased by a local temperature increase due to intense friction during the milling process.

\subsection{Physical and Mechanical Properties}

3.2.1 Density. Table 2 presents the bulk densities taken from three consolidated independent samples obtained after different milling times. The results indicate that ball-milled $\mathrm{Fe}$ alloy powders can be consolidated to near-full density by a 5min hold at $900{ }^{\circ} \mathrm{C}$ under a pressure of $35 \mathrm{MPa}$ using the SPS method.

The as-sintered densities are very high and range between 7.69 and $7.74 \mathrm{~g} / \mathrm{cm}^{3}$. As the $\mathrm{Fe}-\mathrm{Mn}-\mathrm{Cu}-\mathrm{Sn}-\mathrm{C}$ powder could have been oxidized during milling in air, it becomes evident that the processing conditions led to its near-full densification. Despite lower density, the as-sintered specimens made of the powder milled for $120 \mathrm{~h}$ are characterized by a markedly higher hardness, a fine-grained microstructure and a large amount of hard oxides.

3.2.2 Vickers and Knoop Hardness. Hardness results of the experimental Fe alloys are given in Table 2. It has been found that the Vickers hardness markedly increases with

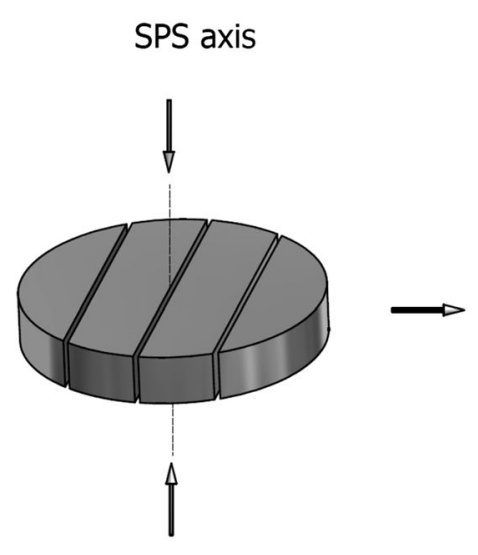

(a)

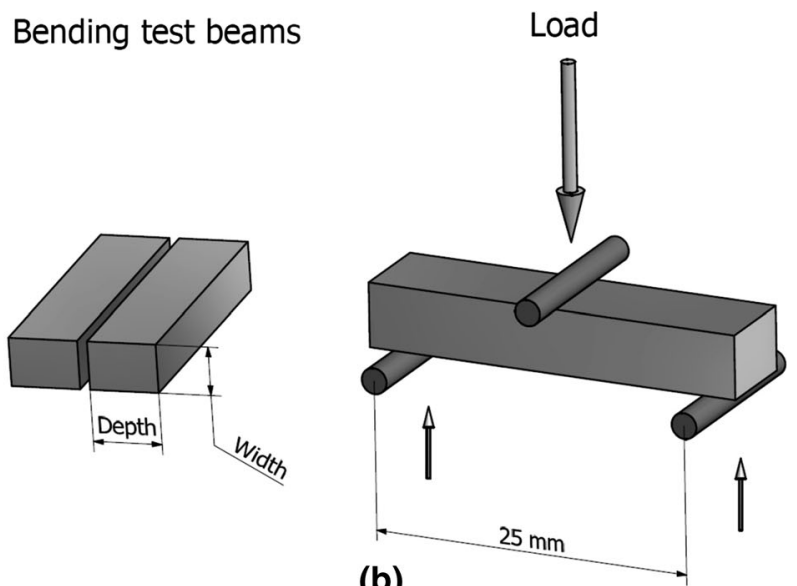

(b)

Fig. 3 Three-point bending test procedure: (a) preparation of test beams, (b) schematic representation of test fixture 

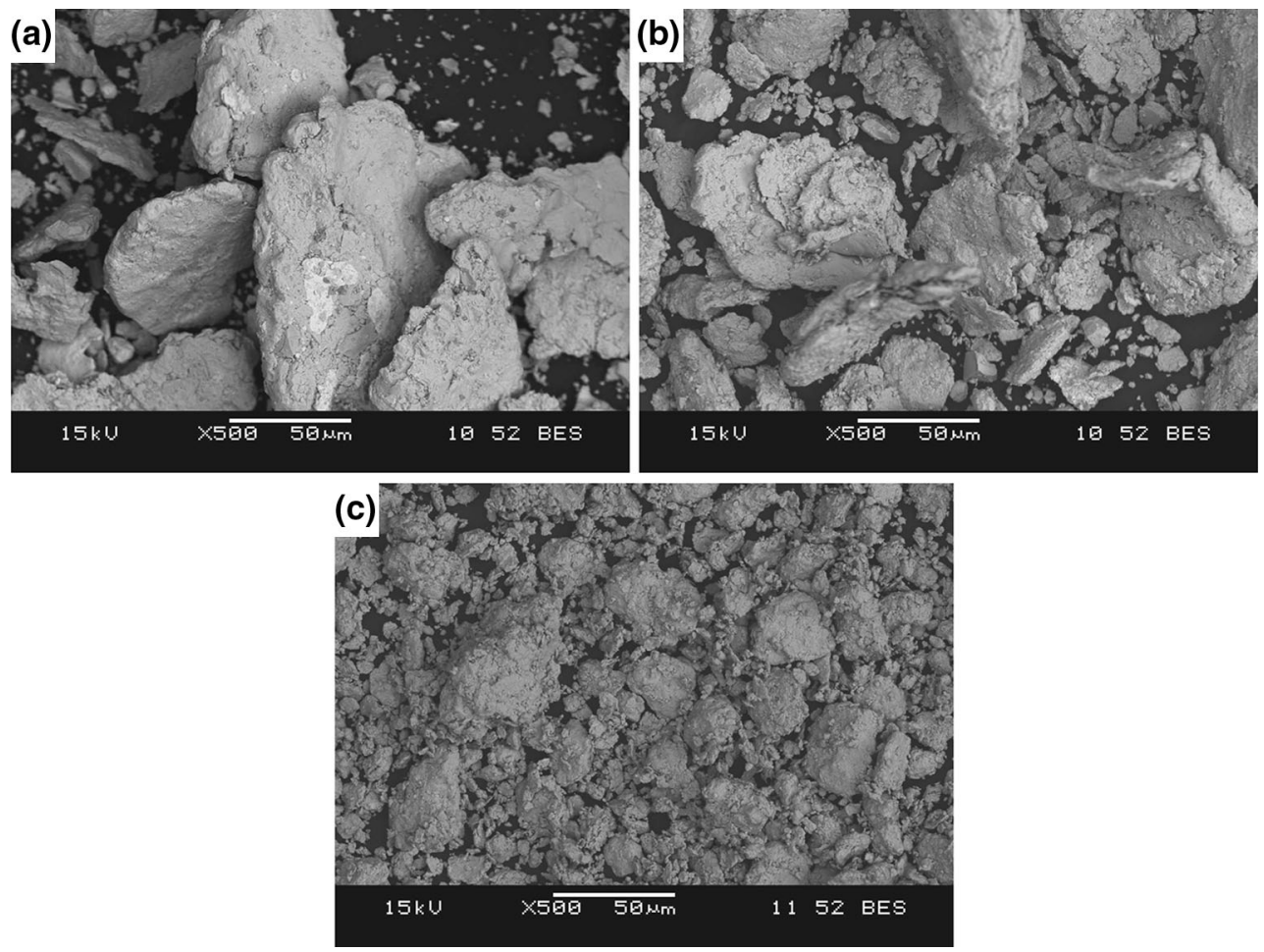

Fig. 4 Fe alloy powders ball-milled for: (a) 8, (b) 30 and (c) $120 \mathrm{~h}$

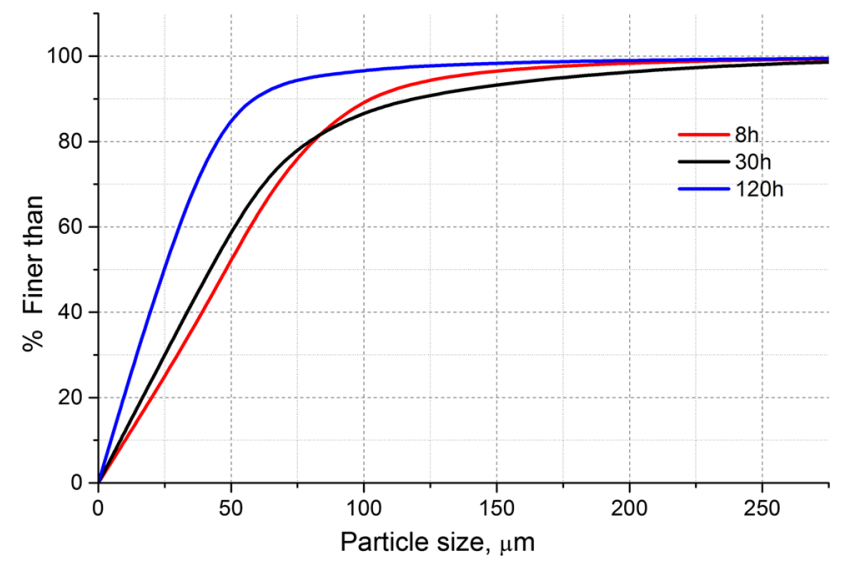

Fig. 5 Particle size distributions of the ball-milled powders plotted cumulatively

milling time. By using the shallow penetration Knoop hardness test, it was possible to determine the degree of strengthening in the subsurface layer of the metallographic specimens. As has been found experimentally (Ref 25), both grinding and polishing produce a plastically deformed layer. Its depth depends on sharpness and size of the abrasive. Grinding and polishing experiments conducted on annealed brass indicate that the plastically deformed layer extends to 77 and $0.7 \mu \mathrm{m}$ after plain grinding on \#220 SiC paper and fine polishing with $1 \mu \mathrm{m}$ diamond, respectively, whereas significant plastic deformation occurs only after grinding and extends down to around $8 \mu \mathrm{m}$ beneath a $2-\mu \mathrm{m}$-thick heavily scratched skin. Therefore,

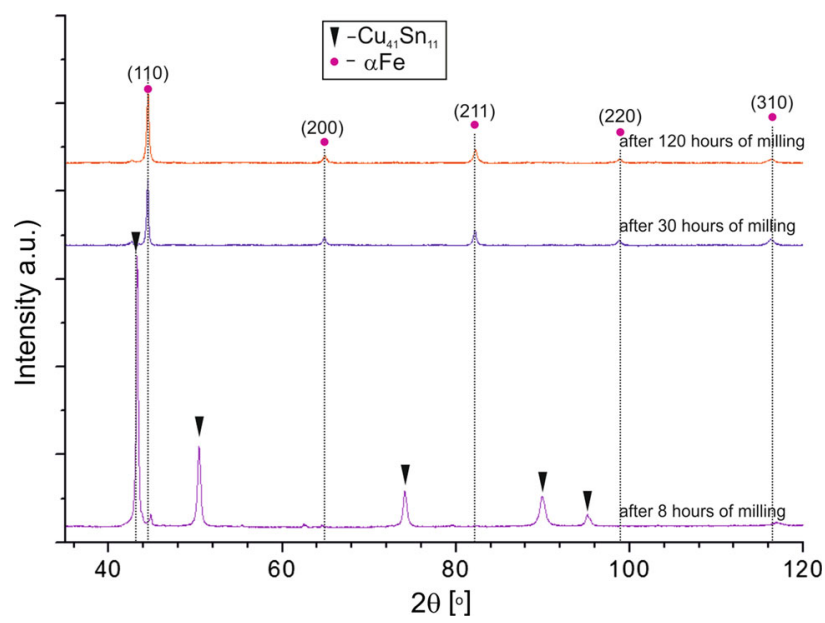

Fig. 6 X-ray diffraction patterns of the powder mixture after milling for 8,30 and $120 \mathrm{~h}$

by using these methods we could quantify the cold work produced by grinding on \#220 SiC paper within the subsurface layer. The Knoop hardness increased from 271, 296 and 317 $\mathrm{HK}$ after polishing to 327,349 and $329 \mathrm{HK}$ after grinding for samples made from powders ball-milled for 8, 30 and $120 \mathrm{~h}$, respectively.

3.2.3 Flexural Strength. The results obtained from threepoint bending (Table 2) indicate that after milling for $30 \mathrm{~h}$, the sintered material was characterized by the lowest bending strength and highest ductility. Prolonged milling, for $120 \mathrm{~h}$, leads to a marked increase in both TRS and OYS, but at the 
Table 2 Densities, Vickers and Knoop hardnesses and bend properties of the experimental alloys

\begin{tabular}{|c|c|c|c|c|c|c|c|}
\hline \multirow[b]{2}{*}{ Milling time, $\mathrm{h}$} & \multirow[b]{2}{*}{ Density (a), $\mathbf{g} / \mathrm{cm}^{3}$} & \multirow[b]{2}{*}{ HV1 (a) } & \multicolumn{2}{|c|}{ HK0.5 (a) } & \multicolumn{3}{|c|}{ Three-point bend test } \\
\hline & & & After polishing & After grinding & TRS, MPa & OYS, MPa & $\varepsilon_{\mathbf{p l}}, \%$ \\
\hline 8 & $7.72 \pm 0.01$ & $309 \pm 32$ & $271 \pm 33$ & $327 \pm 110$ & 1065 & 803 & 1.39 \\
\hline 30 & $7.74 \pm 0.01$ & $312 \pm 15$ & $296 \pm 10$ & $349 \pm 74$ & 1032 & 788 & 1.41 \\
\hline 120 & $7.69 \pm 0.01$ & $319 \pm 9$ & $317 \pm 3$ & $329 \pm 52$ & 1268 & 1197 & 0.64 \\
\hline
\end{tabular}

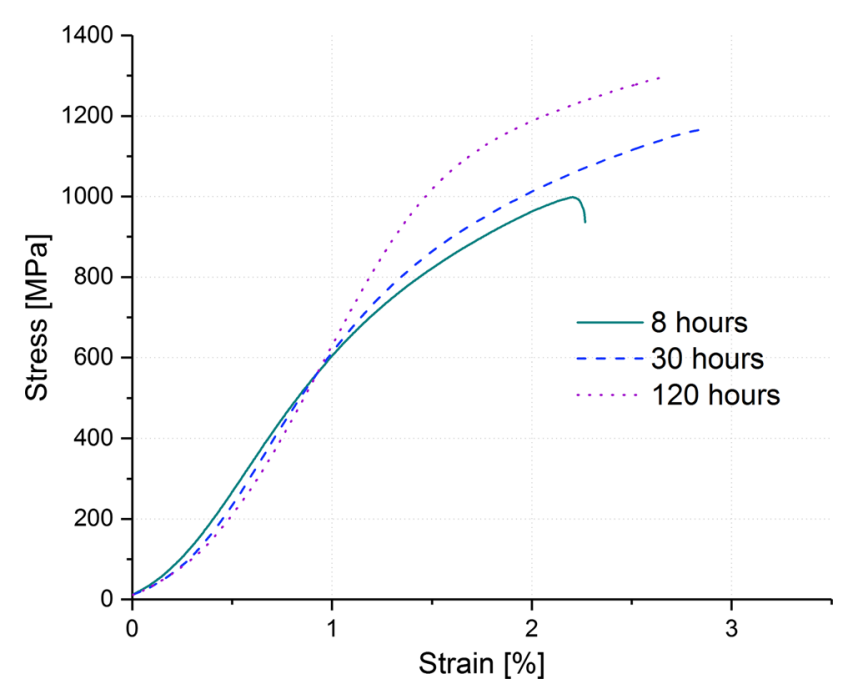

Fig. 7 Typical stress-strain behavior of sintered Fe-Mn-Cu-Sn-C alloy powders after milling for 8,30 and $120 \mathrm{~h}$ expense of significant decreased of ductility. The highest $\sigma_{0.2}$ ( $>1100 \mathrm{MPa}$ ) was obtained for the Fe alloy milled for $120 \mathrm{~h}$, which still retained ductility at an acceptable level. Figure 7 shows selected bend curves of ball-milled Fe alloys. The fracture surfaces of broken bending beams are presented in Fig. 8. The qualitative fractographic investigations revealed a ductile dimple structure irrespective of the milling time of the starting mixture. The variations in the fractographic features between specimens well correlate with their microstructural inhomogeneities. After milling for $8 \mathrm{~h}$, the fracture surface is inhomogeneous with respect to the dimple size and shows few fine faceted and structureless regions (Fig. 8a). After milling for $30 \mathrm{~h}$ and longer, the dimple size becomes very fine (Fig. $8 \mathrm{~b}$ and c).

\subsection{Abrasion Resistance}

The abrasive wear index $\left(A_{i}\right)$, representing the average loss of height of three test pieces per $20 \mathrm{~m}$ sliding distance, was calculated for abrasion by a loose quartz sand finer than $200 \mu \mathrm{m}\left(A_{i(3)}\right)$ and on \#220 $\mathrm{SiC}$ grinding paper $\left(A_{i(2)}\right)$. In both cases, the wear rate was calculated as:
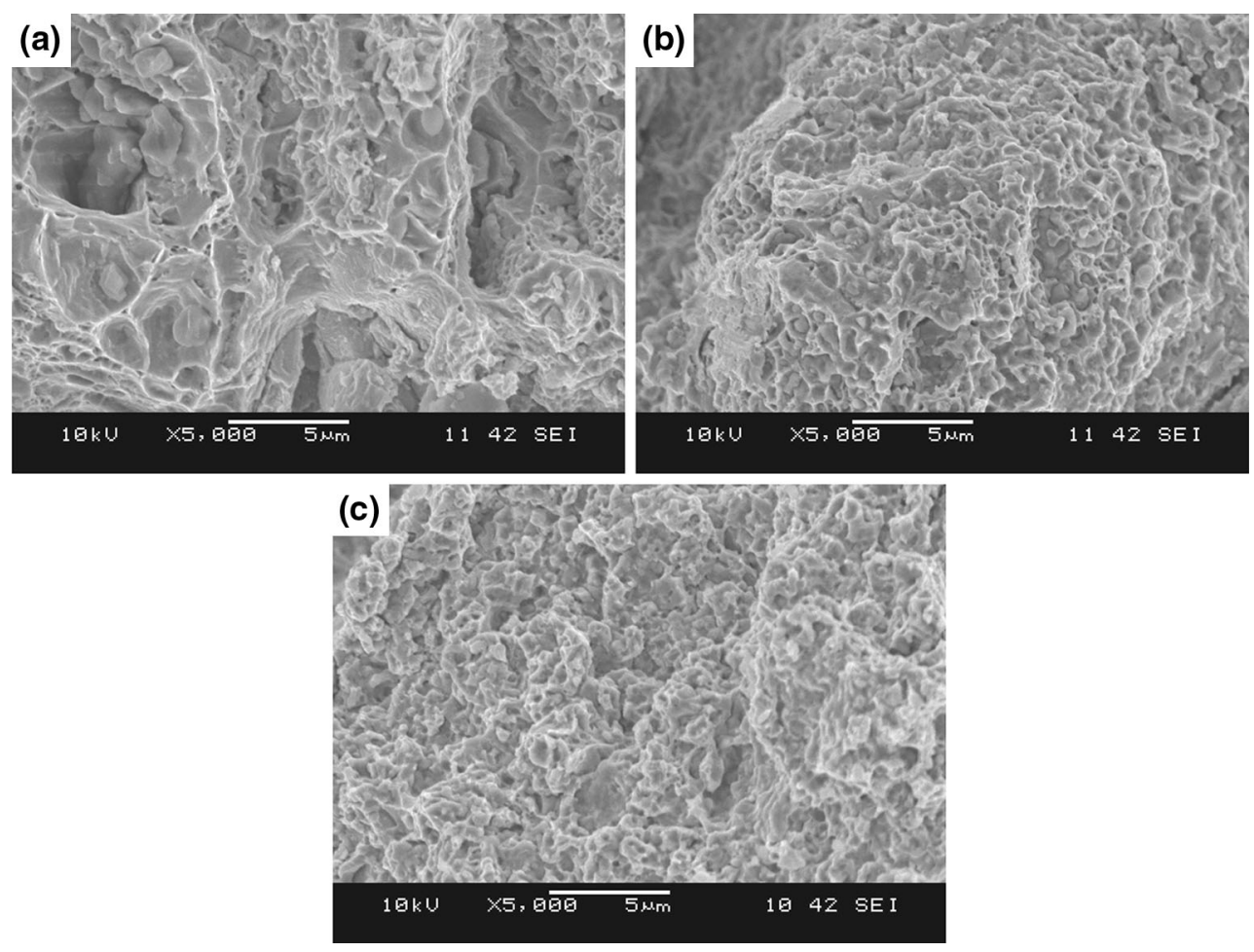

Fig. 8 SEM fractographs of the Fe alloy milled for: (a) 8, (b) 30 and (c) $120 \mathrm{~h}$ 
$\mathrm{V}_{(\gamma \mathrm{Fe}),}, \mathbf{v o l . \%}$ (a)

Milling time, $h$

$A_{i(3)}, \mu \mathrm{m} / 20 \mathrm{~m}$

$A_{i(2)}, \mu \mathrm{m} / 20 \mathrm{~m}$

After polishing

After grinding

$\begin{array}{lrrrr}8 & 34.7 & 170.2 & 71 & 66 \\ 30 & 33.0 & 164.8 & 87 & 77 \\ 120 & 38.8 & 220.2 & 100 & 93\end{array}$

(a) $V_{(\gamma \mathrm{Fe})}+V_{(\alpha \mathrm{Fe})}=100 \%$ (no account taken of other phases)
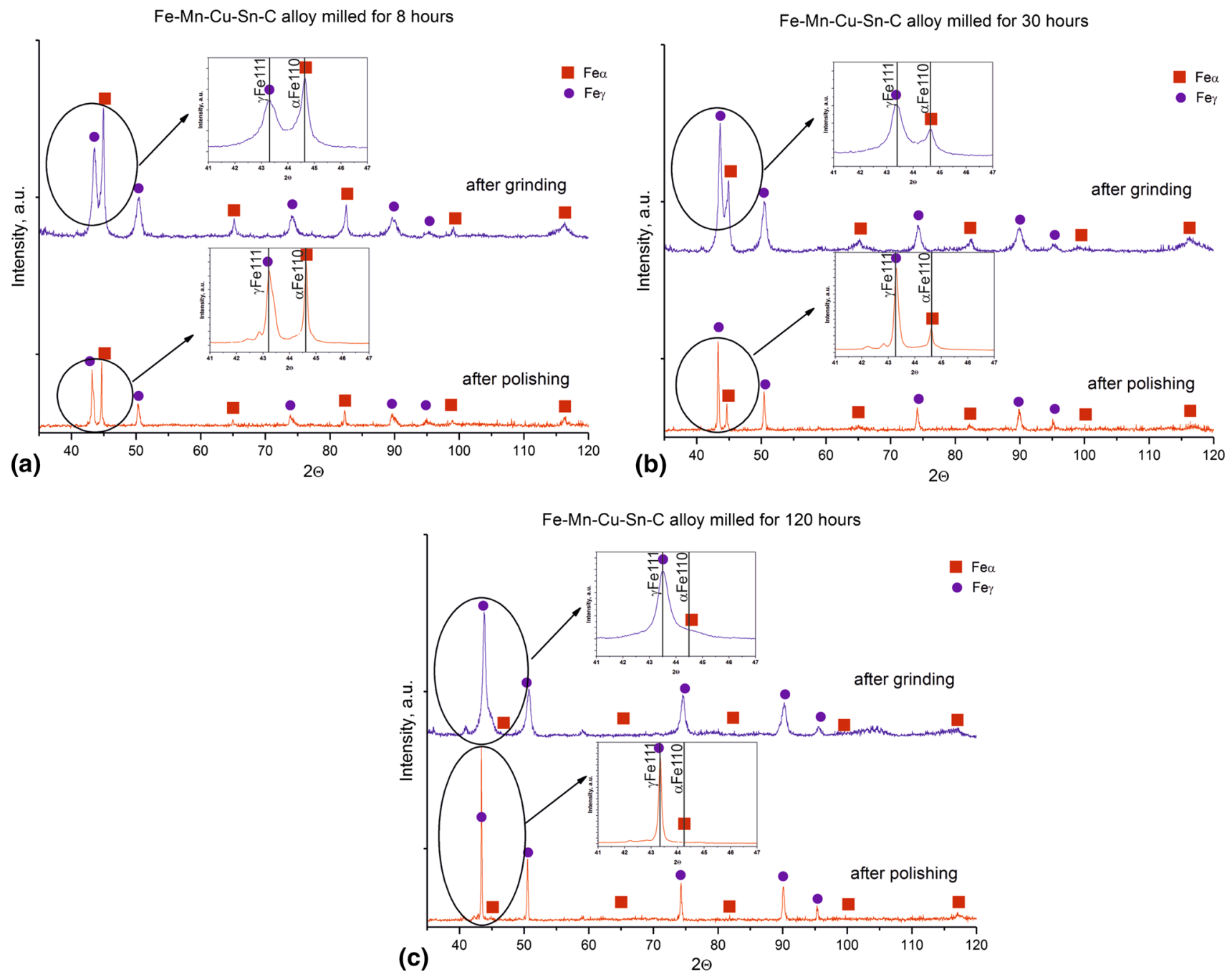

Fig. 9 XRD pattern of sintered Fe-Mn-Cu-Sn-C alloy milled for: (a) 8, (b) 30 and (c) $120 \mathrm{~h}$

$A_{i}=\frac{\sum \Delta M_{i}}{V \cdot A \cdot\left(\rho_{s}+2.38\right)} \cdot 10^{4}\left[\frac{\mu \mathrm{m}}{20 \mathrm{~m}}\right]$

where $\Delta M_{i}$ is mass loss of individual test piece per 20-s wear interval $[\mathrm{g}] ; V$, sliding velocity $[\mathrm{m} / \mathrm{s}] ; A$, wear surface of test specimen $\left[\mathrm{cm}^{2}\right] ; \rho_{s}$, specific density of tested specimen $[\mathrm{g} /$ $\left.\mathrm{cm}^{3}\right]$.

The results of all wear tests are summarized in Table 3 . It can be seen that initially the powder milling process slightly increases resistance of the sintered materials to both two-body and three-body abrasion. Further elongation of milling from 30 to $120 \mathrm{~h}$ markedly decreases abrasion resistance that can be caused by decreased ductility of the material due to progressing oxidation of the powder during milling.

\subsection{X-Ray Diffraction}

An additional quantitative $\mathrm{x}$-ray diffraction phase analysis was carried out to analyze the $(\gamma \mathrm{Fe})$-to- $(\alpha \mathrm{Fe})$ volume fractions 

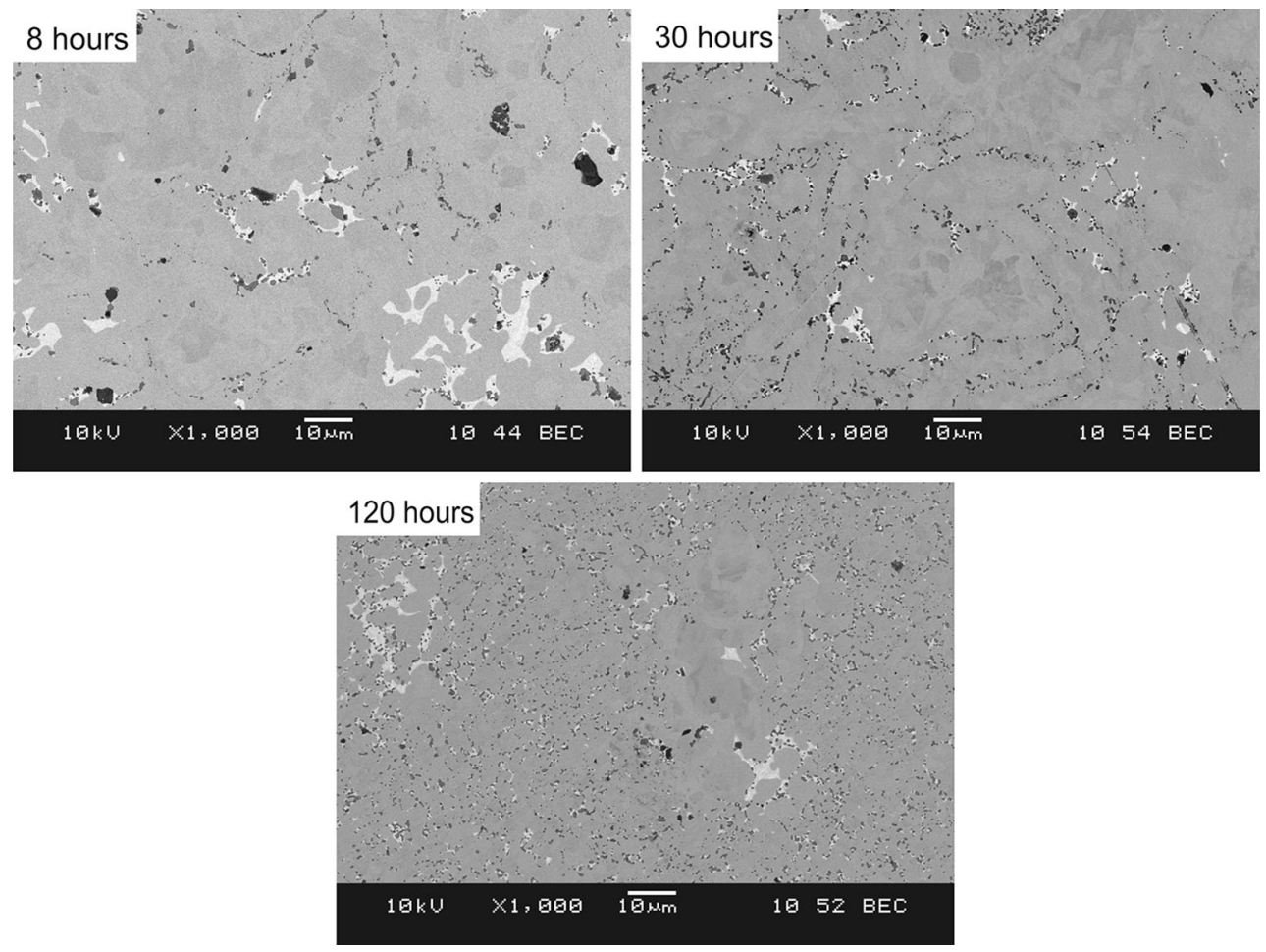

Fig. 10 Evolution of microstructure of Fe-Mn-Cu-Sn-C alloy with milling time

ratio after rough grinding and fine polishing processes in order to study the potential contribution of deformation-induced martensite to material strengthening. $\mathrm{Cu} \mathrm{K}_{\alpha}$ radiation was used and two separate diffraction lines were measured, namely 111 and 110 for the fcc $(\gamma \mathrm{Fe})$ and bcc $(\alpha \mathrm{Fe})$ structure, respectively. The volume fraction of austenite $\left(V_{\gamma \mathrm{Fe}}\right)$ was calculated using the following equation (Ref 23$)$ :

$V_{(\gamma \mathrm{Fe})}=\left[\frac{1.44 \cdot I_{111_{\gamma}}}{I_{110_{\alpha}}+1.44 \cdot I_{111_{\gamma}}}\right] \cdot 100 \%$

where $I_{110_{\alpha}}$ is intensity of 110 diffraction line for $(\alpha \mathrm{Fe}) ; I_{111}$, intensity of 111 diffraction line for $(\gamma \mathrm{Fe})$.

The results of measurements are given in Table 3, whereas the XRD patterns of sintered $\mathrm{Fe}-\mathrm{Mn}-\mathrm{Cu}-\mathrm{Sn}-\mathrm{C}$ alloys are presented in Fig. 9.

The combined additions of $12 \mathrm{wt} \%$ manganese and 0.6 wt. $\%$ carbon resulted in a marked amount of retained austenite, which was increasing with milling time from 66 to 93 vol. \% in alloys ball-milled for 8 and $120 \mathrm{~h}$, respectively (Table 3$)$. Virtually no $(\alpha \mathrm{Fe})$ was found in the sintered material produced from the powder ball-milled for $120 \mathrm{~h}$. The retained austenite seems to be fairly stable. Plastic deformation caused by grinding on the $\mathrm{SiC}$ paper had only a limited effect on the amount of deformation-induced martensite as compared with Fe-Ni-based materials described in Ref 6-9, where the retained austenite is unstable and its major part is transformed to highcarbon martensite under tribological straining. This implies that other mechanisms, such as deformation twins or planar dislocation structures (Ref 26, 27), may contribute to strain hardening during abrasion; this will be explained in further studies.

\subsection{Microstructure}

The microscopic observations showed major differences in grain size and microstructural homogeneity of specimens made from powders milled for 8,30 and $120 \mathrm{~h}$. As documented in Fig. 10, the microstructure refines with milling time but retains its chemical inhomogeneity. After $8 \mathrm{~h}$ of milling, there are numerous areas enriched in manganese. Increased milling time of the starting powder mixture resulted in a reduction in the average particle size and a better distribution of manganese and other alloying elements, as shown in the elemental MAP analysis (Fig. 11a and b).

\section{Conclusions}

1. The investigated Fe-Mn-Cu-Sn-C alloy powders can be consolidated to near-full density by SPS for $5 \mathrm{~min}$ at $900{ }^{\circ} \mathrm{C}$ under a moderate pressure of $35 \mathrm{MPa}$.

2. The volume fraction of retained austenite in as-sintered material increases in proportion to ferrite with milling time to reach $100 \%$ after milling for $120 \mathrm{~h}$. The majority ( $\sim 90 \%)$ of austenite resists deformation-induced transition to martensite, but the subsurface layer of the material work-hardens during grinding.

3. Vickers hardness and bending strength increase with milling time at the expense of ductility. After prolonged milling, the TRS and OYS reach high values of 1268 and $1197 \mathrm{MPa}$, respectively, and the material still fails in a ductile manner.

4. The wear tests which involve three-body abrasion and two-body abrasion rank the examined matrix alloys in 

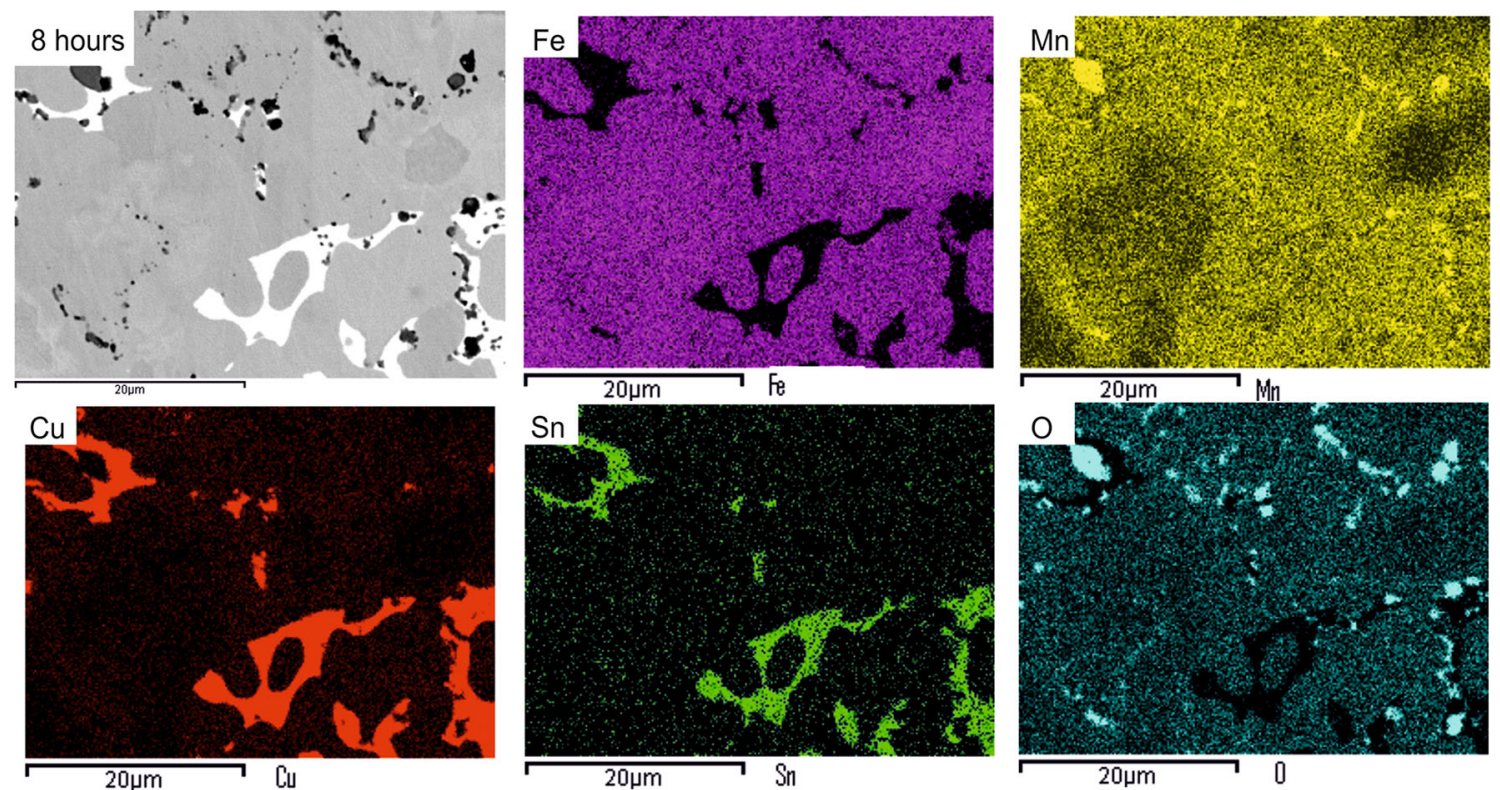

(a)
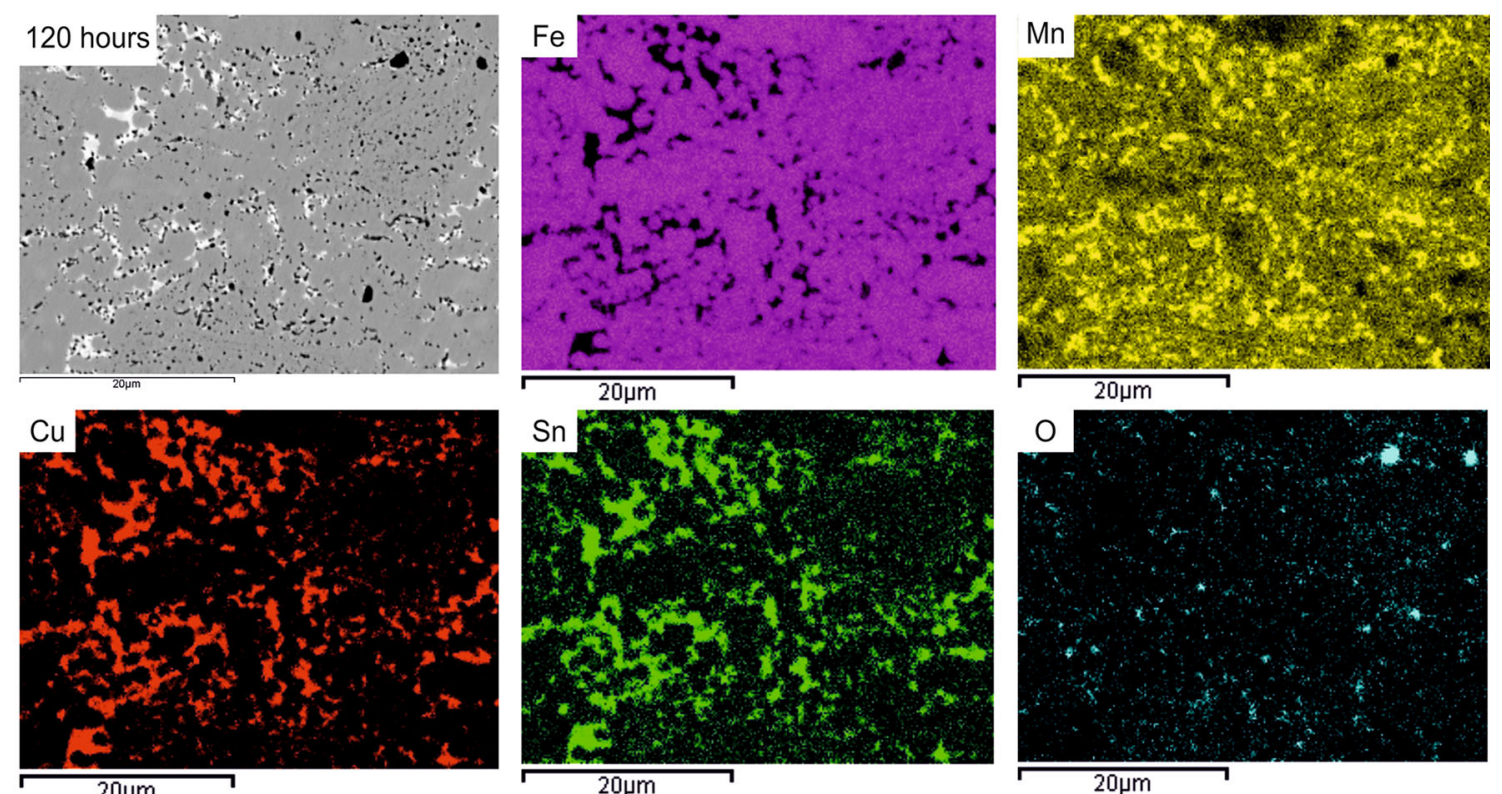

(b)

Fig. 11 EDS maps acquired on specimen made from powder milled for: (a) $8 \mathrm{~h}$ and (b) $120 \mathrm{~h}$

the same order. A marked increase in the rate of abrasion was obtained after milling for $120 \mathrm{~h}$.

In view of the obtained results, the $\mathrm{Fe}-\mathrm{Mn}-\mathrm{Cu}-\mathrm{Sn}-\mathrm{C}$ alloy obtained from powders ball-milled between 8 and $30 \mathrm{~h}$ has high commercial potential for replacing $\mathrm{Co}-\mathrm{WC}$ matrices in sintered diamond tools.

\section{Acknowledgments}

The study was performed under Preludium Research Project No. UMO-2015/19/N/ST8/01050. Project was financed by the National Science Centre, Poland.

\section{Open Access}

This article is distributed under the terms of the Creative Commons Attribution 4.0 International License (http://creativecommons.org/ licenses/by/4.0/), which permits unrestricted use, distribution, and reproduction in any medium, provided you give appropriate credit to the original author(s) and the source, provide a link to the Creative Commons license, and indicate if changes were made.

\section{References}

1. J. Konstanty, Sintered Diamond Tools: Trends, Challenges and Prospects, Powder Metall., 2013, 56, p 184-188

2. B.J. Kamphuis and J. Peersman, Pre-Alloyed Bond Powders, Patent US 707788, 2006 
3. I.E. Clark and B.J. Kamphuis, Cobalite HDR-A New Prealloyed Matrix Powder for Diamond Construction Tools, Ind. Diam. Rev. 2002, 62, p 177-182

4. B.J. Kamphuis and A. Serneels, Cobalt and Nickel Free Bond Powder for Diamond Tools: Cobalite CNF, Ind. Diam. Rev., 2004, 64, p 26-32

5. A.P. Barbosa, G.S. Bobrovnitchii, A.L.D. Skury, R.S. Guimarães, and M. Filgueira, Structure, Microstructure and Mechanical Properties of PM Fe-Cu-Co Alloys, Mater. Des., 2009, 31, p 522-526

6. A. Romański, J. Konstanty, and W. Ratuszek, New Fe-Ni and Fe-Mn Powders Used in Manufacturing Diamond Tools, Appl. Mech. Mater, 2013, 431, p 3-7

7. J. Konstanty, A. Romański, E. Bączek, and D. Tyrała, New Wear Resistant Iron-Base Matrix Materials for the Fabrication of Sintered Diamond Tools, Arch. Metall. Mater., 2015, 60, p 633-637

8. A. Romański and J. Konstanty, Ball-Milled Fe-Ni and Fe-Mn Matrix Powders for Sintered Diamond Tools, Arch. Metall. Mater, 2014, 59, p $1-7$

9. J. Konstanty and A. Romański, New Nanocrystalline Matrix Materials for Sintered Diamond Tools, Mater. Sci. Appl., 2012, 3, p 779-783

10. L.J. de Oliviera, G.S. Bobrovnitchii, and M. Filgueira, Processing and Characterization of Impregnated Diamond Cutting Tools Using a Ferrous Metal Matrix, Int. J. Refract. Metals Hard Mater., 2007, 25, p 328-335

11. J. Konstanty, Powder Metallurgy Diamond Tools, Metal Powders Technology, Elsevier, Oxford, 2005

12. J. Konstanty, Cobalt as a Matrix in Diamond Impregnated Tools for Stone Sawing Applications, AGH University of Science and Technology, Krakow, 2002

13. W. Tillmann, C. Kronholz, M. Ferreira, A. Knote, W. Theisen and P. Schütte P, Comparison of Different Metal Matrix Systems for Diamond Tools Fabricated by New Current Induced Short-Time Sintering Processes, PM2010 World Congr.-Diam. Tools. Manuscr. Ref. by Dr José M Sanchez, CEIT, Spain, 2010

14. J. Schmidt, A. Knote, M. Armbrüster, and Th Weißgärber, Spark Plasma Sintering of Diamond Impregnated Wire Saw Beads, Diam. Appl. Technol., 2011, 64, p 35-40
15. D. Handtrack, F. Despang, B. Kieback, N. Reinfried, and Y. Grin, Fabrication of Ultra-Fine Grained and Dispersion-Strengthened Titanium Materials by Spark Plasma Sintering, Mater. Sci. Eng., 2006, 437, p 423-429

16. J. Schmidt, Th. Weißgärber, and T. Schubert, Spark Plasma Sintering of Intermetallics and Metal Matrix Composites, Euro PM2005 Sinter. II, 2005

17. X. Zhou, Y. Wang, T. Li, X. Li et al., Fabrication of Diamond-SiC-TiC Composite by a Spark Plasma Sintering-Reactive Synthesis Method, J. Eur. Ceram. Soc., 2015, 35, p 69-76

18. C. Luo, X. Qi, C. Pan, and W. Yang, Diamond Synthesis from Carbon Nanofibers at Low Temperature and Low Pressure, Sci. Rep., 2015, 5, p 13879

19. S. Grasso, Ch Hu, G. Maizza, and Y. Sakka, Spark Plasma Sintering of Diamond Binderless WC Composites, J. Am. Ceram. Soc., 2012, 95, p 2423-2428

20. D.L. Yunga, S. Cygan, M. Antonova, L. Jaworska, and I. Hussinova, Ultra High-Pressure Spark Plasma Sintered $\mathrm{ZrC}-\mathrm{Mo}$ and $\mathrm{ZrC}-\mathrm{TiC}$ Composites, Int. J. Refract. Metals Hard Mater., 2016, 16, p 201-206

21. A. Knaislova, P. Novak, S. Cygan, L. Jaworska, and M. Cabibbo, High-Pressure Spark Plasma Sintering (HP SPS): A Promising and Reliable Method for Preparing Ti-Al-Si Alloys, Materials, 2017, 10(5), p 6-13

22. E. Fundal, The Struers Micro Wear Test, Structure, 1989, 3, p 3-4

23. J. Konstanty and D. Tyrała, Wear Mechanism of Iron-Base DiamondImpregnated Tool Composites, Wear, 2013, 303, p 533-540

24. J. Konstanty, T.W. Kim, and S.B. Kim, Resistance to Abrasive Wear of Materials Used as Metallic Matrices in Diamond Impregnated Tools, Mater. Sci. Forum, 2007, 534-536, p 1125-1128

25. K. Geels, The True Microstructure of Materials, Structure, 2000, 35, p 513

26. S. Vercammen, B. Blanpain, B.C. De Cooman, and P. Wollants, Cold Rolling Behaviour of an Austenitic Fe-30Mn-3Al-3Si TWIP-Steel: the Importance of Deformation Twinning, Acta Mater, 2004, 52, p 205-2012

27. P.H. Adler, G.B. Olson, and W.S. Owen, Strain Hardening of Hadfield Manganese Steels, Metall. Trans. A, 1986, 17A, p 1725-1737 